Capítulo 7 



\title{
Narrativas y tecnicidades mediáticas: claves para comprender la experiencia subjetiva contemporánea*
}

\author{
Ana Brizet Ramírez Cabanzo
}

\section{Resumen}

Este artículo propone mirar con detenimiento cómo la configuración subjetiva contemporánea anida otras narrativas diferentes a la moderna, a causa de las interacciones que los sujetos hoy mantienen en el escenario cibercultural. En la primera parte se despliega el carácter de la narrativa en el marco de las capacidades del sujeto. En la segunda, se analiza cómo a través de los nuevos repertorios tecnológicos, están emanando tecnicidades mediáticas - sobre todo en las nuevas generaciones- que imprimen diversidad y pluralidad a la experiencia de sí. Finalmente, se plantea un cierre con algunos elementos para tensionar la relación comunicación-educación, desde estas coordenadas, con énfasis en el actual capitalismo cognitivo.

\section{Las narrativas como tejido de la experiencia subjetiva contemporánea}

Las narrativas configuran el lugar de producción del sujeto, al entrelazar sus relatos, sus procesos identitarios y la condición dialógica intersubjetiva, como marco de

* Este artículo hace parte de las reflexiones teóricas de la tesis doctoral Infancia(s), tecnicidades mediáticas y narratividades (2011-2017), cuya asesora es Rocío Rueda Ortiz, en el marco del Doctorado Interinstitucional en Educación de la Universidad Pedagógica Nacional (énfasis: Educación, Cultura y Desarrollo; grupo de investigación: Educación y Cultura Política; línea: Cibercultura y Educación).

** Especialista en Lúdica para el Desarrollo Cultural, magister en Investigación Social Interdisciplinaria de la Universidad Distrital Francisco José de Caldas. Correo electrónico: anabrizet@gmail.com 
apertura a la enunciación de la vida misma. En este sentido, manifiestan el espacio autobiográfico que emerge en aras de la permanente constitución y redefinición del sujeto como actor social.

En la medida que los sujetos ejercen la posibilidad de narrarse y ser narrados por otros, su voz y sus testimonios dan cuenta de su experiencia en los relatos, en historias que nunca se terminan de contar (Arfuch, 2002, p. 18). Así, se va constituyendo el tejido de la subjetividad, pues a través de las narrativas, el sujeto va cobrando espacialidades y temporalidades particulares que le permiten constituirse en la trama sociocultural de la incompletud y la otredad (Ricoeur, 1995).

De esta manera, el sujeto que se narra afirma su subjetividad, en tanto se posiciona simbólica, ética, social, cultural y políticamente en una producción de sentido que se aprehende desde la infancia. A través de cada relato, ordena y reestructura su experiencia, y se hace sujeto narrativo, que, en palabras de Nietzsche,

[...] es capaz de realizar promesas, de "recordar hacia delante" así como hacia atrás, y de vincular un final con su principio de modo que atestigüe una "integridad" que debe poseer todo individuo para convertirse en "sujeto" de un sistema de legalidad, moralidad o propiedad cualquiera. (Barthes, citado en White, 1992, p. 54)

Las dimensiones de lo imaginario y lo real legitiman las diversas representaciones narrativas como alusiones de una conciencia que agrupa las percepciones del mundo, sus estructuras temporales y espaciales, y los sentidos construidos en sus procesos de representación y significación de la narratividad.

Sin duda, la capacidad narrativa se apoya en la propiedad de la enunciación (Benveniste, 1978), que la dispone como eje articulador de la vivencia del sujeto, en la que se manifiesta "una aptitud paralela para desdoblarse en tiempo del acto de narrar y tiempo de las cosas narradas" (Ricoeur, 1995a, p. 380), para moverse en múltiples realidades que escapan a los límites de la condición lingüística y a su mera literalidad como habilidad. De la mano de Paul Ricoeur (1995-2006), asumimos la narrativa como categoría de la práctica social que establece relaciones con la acción y las capacidades del sujeto, a través de la actividad mimética que confiere la narración, y que alude al "quién es el autor y agente" de esa historia contada de la cual nos habla Hannah Arendt.

En otras palabras, las narrativas representan las modalidades de acción de los sujetos: sus formas de agenciar, los agenciamientos mismos de sus poderes — del poder ser y de lo que es capaz de hacer-, y los relatos que en estos son articulados y entrecruzados - relatos de ficción, historia y realidad que refieren su armazón ontológica-. Es desde su capacidad de mímesis, como categoría tomada inicialmente de Aristóteles, que el sujeto deviene creador del mundo y productor 
de sí, como ipseidad ${ }^{1}$. Tal capacidad permite que el sujeto vaya y vuelva, y, por ende, ese regreso es refigurado, transformado en otro, completado, pero incompleto a la vez. Con ello, el círculo hermenéutico muestra cómo el sujeto deviene como tal en la narración sobre el plano práctico, como nos diría Ricoeur, sobre el mundo humano de la acción, que como drama y padecimiento, acontecen en la cotidianidad.

En este marco de ideas, Ricoeur (2004) desarrolla un despliegue fenomenológico sobre el ser capaz, para describir cómo las capacidades, sean innatas o adquiridas, constituyen el conjunto de poderes básicos que otorgan al ser su carácter de humanidad, para padecerse en su historia personal y, así, entramarse en las innumerables historias de los otros. Allí, en esta trama del narrar, se halla la marca de la temporalidad de la identidad personal como constitutiva, pues es la historia la que define a la persona, la hace y la constituye.

Según lo anterior, son "la capacidad de decir, de actuar, de contar, de ser imputable y la de ser promesa" (Ricoeur, 2004) las que ponen a prueba al sujeto y lo explicitan como sujeto capaz y como sujeto responsable, al mostrarse, exteriorizarse y dar testimonio de sus capacidades. Así, el sujeto adquiere, a través de la narración, la posibilidad de narrarse una y otra vez, de entramarse con otros a partir de la confianza de lo que es capaz y de lo que puede hacer en un contexto social que lo georreferencia y lo afirma.

A través de la capacidad del poder decir, el individuo "produce espontáneamente un discurso sensato" (Ricoeur, 2004), que se caracteriza por estar dirigido a un alguien que cuestiona, escucha, responde o dialoga; por tener reglas comunes y por remitir a un sentido sobre algo. El poder actuar, como la capacidad de intervenir sobre la sociedad y la naturaleza, hace posible que el individuo sea artesano de la vida, "introduciendo la contingencia humana, la incertidumbre y lo imprevisible en el curso de las cosas" (Ricoeur, 2004) y de las acciones de los otros. El poder contar se posiciona como la capacidad de hacer legible e inteligible los acontecimientos, cuando se cuentan dentro de una historia y, en consecuencia, se articulan a la historia de los relatos vitales de los otros. El arte del contar siempre implica un otro a quien se cuenta, un otro que le cambia a sí mismo y que le permite desplegarse en el relato, y así ocurrir en la interlocución y la creación intersubjetiva.

La imputabilidad, afirma Ricoeur (2004), "constituye una capacidad claramente moral" que identifica al agente humano como "verdadero autor de sus actos", que lo responsabiliza y lo sitúa en la afirmación consecuente de sus acciones y, por ende, en una vuelta a la acción para acontecer de otro modo posible.

1 En el texto La identidad narrativa, Ricoeur (1999) problematiza la identidad desde la noción de sí mismo, donde se encuentran los sentidos idem e ipse. El primero significa 'inmutable', y el segundo, 'propio a lo largo del tiempo'. Es en el sentido de la identidad como ipseidad que el autor desarrolla su teoría de la identidad narrativa, alrededor de la cual posiciona reflexivamente las capacidades del sujeto. 
En este sentido, el ser humano, como sujeto responsable, tiene la capacidad de ser promesa, de registrarse y atestiguarse a un otro a partir del compromiso de la confianza sobre su palabra como proyección del futuro, el cual puede darse o no.

Si se tiene en cuenta que las transformaciones a las que estamos abocados hoy se están dando en medio de profundos cambios, vale la pena preguntarse por cómo estas capacidades están mutando, máxime si situamos que niños, jóvenes y adultos interactúan en el contexto de la digitalización de la cultura, la globalización económica, las sociedades de mercado y el consumo de las industrias culturales. El sujeto, en este panorama, no solo se instala ante otra configuración subjetiva; también se halla ante modalidades de narración que le confieren ser de otro modo posible, diverso y descentrado. Sus procesos de significación y comunicación, tanto individuales como colectivos, hallan otras fuentes de sentido y, por lo tanto, de experiencia.

\section{Los nuevos repertorios tecnológicos como vivencia cultural y fuente de sentido de otras tecnicidades mediáticas}

El creciente papel de las tecnologías de la información y la comunicación en la configuración de las sociedades exige concebirlas en relación con las fuerzas y transformaciones políticas, económicas y culturales que, en permanente tensión, están enmarcando el devenir particular de los sujetos y sus prácticas concretas de producción de sí.

No se puede desconocer que los estilos de vida, los patrones de consumo, los circuitos de comunicación, los sujetos y las instituciones que los regulan hoy transitan en una multiplicidad de pantallas que las industrias culturales ofrecen a las nuevas generaciones; con ello, las formas de comunicación, ocio, aprendizaje, conocimiento, expresión, participación, creación de realidades posibles, transmisión, difusión y producción de información, entre otros aspectos, se asocian con los desarrollos que las tecnologías tradicionales o domésticas de la radio, la televisión, la prensa y la telefonía han logrado con la digitalización. En tal sentido, los dispositivos, cada vez más convergentes entre unas y otras tecnologías, están adquiriendo formas híbridas de contenido, usos, ensambles, modificaciones y avances en la Web 3.0, y, por ello, en estos momentos se hace significativo hablar de nuevos repertorios tecnológicos.

Antes de entrar a conceptualizar los ambientes comunicativos de la Web 3.0, vale la pena diferenciar los diversos momentos de la web. Se llama Web 1.0 al ambiente comunicativo que permitió tener acceso a información hipertextual que circulaba en la red. La Web 2.0 es una generación de servicios en línea que promueve la participación de los usuarios a través de la colaboración, la interactividad 
y la posibilidad de compartir y clasificar contenidos. La Web 3.0 "sería el resultado de la convergencia receptor/emisor, lector/autor, de la interacción semántica entre bases de datos y máquinas inteligentes" (Muñoz, 2010, p. 10); convergencias que van más allá de las tecnológicas por cuanto intervienen con sus nuevos lenguajes y formatos, las cotidianidades de producción, circulación y consumo cultural, $y$, por ende, los universos de significado estético, expresivo, narrativo, político, económico y social de los sujetos, dando lugar a los "nuevos medios", caracterizados por las "capacidades para mediatizar los contenidos" (Igarza, 2008, p. 152), y manifestados en "las redes sociales, las relaciones entre real/virtual, la solidaridad entre colectivos inteligentes en la red, las tecnologías polifuncionales y móviles, la digitalización y la interactividad" (Muñoz, 2010, p. 10).

A medida que los nuevos medios adquieren otros modos de representar la realidad, se diferencian de lo que fueron otras tecnologías y medios de comunicación, por la modificación de sus códigos, lógicas, formatos de expresión, modos de emisión y recepción, canales, tamaños y funciones. Los medios convencionales no desaparecen, sino que se reconfiguran en nuevos dispositivos que, al combinar atributos de los soportes mediáticos, funcionalidades de unos y de otros - fijos y móviles-, y términos de adaptabilidad y servicios, según las necesidades e intereses de los usuarios a través de la red digital, permiten que los sujetos entablen con estos órdenes de significación distintos; todos convergen y se actualizan en una sola posibilidad cada vez más portable y dinámica, que localiza al sujeto como protagonista y gestor de su propia vida, es decir, un agente activo del curso de la comunicación e información en cuanto a la recepción, producción y emisión de contenidos.

Las tecnologías digitales no pueden concebirse como meros aparatos e instrumentos, sino como "sustratos constitutivos de la subjetividad individual y colectiva, y en consecuencia, constitutivos y constituyentes de nuestras sociedades, pues son exteriorización de nuestra memoria y resguardo de la experiencia (de los saberes más cotidianos, hasta los más objetivados de las ciencias" (Rueda, 2012, p. 44). De esta génesis, emana un conjunto de capacidades, narrativas y modos de expresión de los sujetos que se pliegan en sus trayectorias vitales, en tanto amalgaman sus potencialidades intelectuales, corpóreas y afectivas, en un aliento inmaterial de lazos de cooperación, producción y procesos de creatividad social cada vez más afines.

La convergencia digital se convierte entonces en el escenario de despliegue de la potencia creadora de sujetos, donde niños, niñas y jóvenes ya no solo son consumidores de medios; ahora, con los nuevos medios que convergen en un solo dispositivo, simultáneamente pueden acceder, producir, publicar y recibir por sí mismos también un sinnúmero de información, saberes y experiencias de entretenimiento en diversidad de formatos y contenidos, para compartirlas y recrearlas, 
encontrando otros roles sociales. Al respecto, la convergencia digital va a ser esa cualidad constitutiva del nuevo espacio simbólico y cultural, producto de

[...] la necesidad de vincular continentes con contenidos, como de explorar tecnológicamente las potencialidades de las tecnologías de la información y la comunicación para ofrecer servicios que sean "transparentes" para el espectador: este los recibe sin darse cuenta de cómo, en una misma plataforma, convergen diversas tecnologías; por ejemplo, recibir música, mensajes escritos o videos a través del teléfono portátil de tercera generación y, en tiempo real, responderlos o enviarlos a múltiples correos electrónicos. Es decir, diversas tecnologías, creadas de manera separada en sus inicios, convergen en un solo canal. (Rueda, 2009, p. 117)

Igarza (2008), en coherencia con este planteamiento, describe que a la Convergencia 3.0 pertenecen los nuevos medios sociales y la cuarta pantalla (los celulares), los cuales tienen como rasgos comunes la elasticidad, para expandir sus contenidos y servicios; la permeabilidad ante la renovación dinámica de contenidos originarios de otras plataformas; la predictibilidad frente a las rutas de navegación; la multimodalidad de canales comunicativos y sensoriales en la construcción de significado; la interactividad desde donde los usuarios pueden actuar inmediata o diferidamente; la automaticidad, y la accesibilidad del contenido.

Existen debates sobre cómo nominar estas nuevas tecnologías y, siguiendo los trabajos que se han desarrollado en el Grupo de Educación y Cultura Política en la línea de Cibercultura y Educación de la Universidad Pedagógica Nacional, retomamos la noción de nuevos repertorios tecnológicos (NRT), planteada por Gómez (2010), la cual se expresa en la miniaturización de los componentes de algunos dispositivos, la convergencia digital que involucran, las múltiples y simultáneas funciones sociotecnológicas que cumplen, y el requerimiento orgánico y subjetivo del usuario para situarse ante su polifuncionalidad en tiempo real y expandido, para coordinar híbridamente "acciones, trabajo y experiencia humana de máquinas con máquinas, de máquinas con hombres, de hombres con hombres" (Gómez, 2010, p. 43).

Gómez (2010, p. 45) plantea que los NRT como el teléfono móvil, el chat, el correo electrónico y las páginas de redes sociales se constituyen también como ambientes educativos de aprendizaje y creatividad. Estos estructuran regímenes discursivos de representación que intervienen en la construcción de significado y sentido estético de la vida cotidiana de los sujetos que interactúan con la convergencia digital. Con ello, agencian otras formas de sensibilidad, experiencia sociocultural y acción cognitiva; constituyen nuevas subjetividades y formas de creatividad que integran y desarrollan "competencias intelectuales, lenguajes y sistemas notacionales conquistados por las historias sociales e individuales de las personas" (p. 45). 
En consecuencia, los NRT, en tanto escenarios de expresión, aprendizaje y creatividad, procuran ensambles enunciativos hipermediales que favorecen la puesta en escena de las capacidades de niños y jóvenes, donde no siempre hay un direccionamiento adulto, sino procesos de exploración, aprendizaje entre pares y, en general, autodidactismo (Buckingham, 2008; Rueda, 2008, 2009, 2011). $\mathrm{Al}$ respecto, es la interactividad, como característica fundamental de los nuevos medios, la que permite posibilidades de indagación autodirigida, intervención y creación colaborativa, por cuanto esta se origina en la digitalización de "condiciones de inmediatez, personalización, ampliación de saber o complementariedad, no linealidad y participación en línea”, según Igarza (2008).

Al igual que Buckingham (2002), Martín-Barbero (1999, 2002), Rueda (2012) y Gómez (2010), insistimos en que es necesario entender los NRT no como tecnologías aisladas, sino como entornos que se componen de sistemas de organismos vivos y no vivos, vínculos afectivos, escenarios tecnológicos, recursos materiales, temporalidades sociales, lenguajes, dinámicas de actualización, entre otros. Estos varían según el tipo de interacciones que mantiene cada sujeto con ellos y, por lo tanto, la experiencia social se encuentra difusa y descentrada, múltiple y diversa.

Lo que acontece con los NRT se produce, en palabras de Martín-Barbero (2003), en ecosistemas comunicativos, y propicia la configuración de nuevas tecnicidades mediáticas a la experiencia humana, que la van embebiendo de la mixtura entre lo tipográfico, lo audiovisual y lo digital, y la localizan en la segunda alfabetización (2003, p. 52), en la cual se pluralizan no solo los alfabetos, sino también los relatos, las interacciones y las formas de subjetividad, con los flujos de intercambio entre la técnica, el consumo y el actual capitalismo informacional. De este modo, las tecnicidades mediáticas que se ocasionan en medio de la vivencia cibercultural hoy son diferentes a las producidas con otras técnicas, y, por ende, se están favoreciendo otros modos de sensibilidad, maniobra y creatividad, y otros modos de ser del ser, que están redefiniendo las relaciones particulares que mantenemos no solo con los artefactos técnicos y tecnológicos, sino también con el andamiaje sociocultural que los soporta.

En otras palabras, el mundo de la experiencia humana ahora se va impregnando de la digitalización, procurando otros modos de vida, de relación y, por ende, de sujeto, porque lo que allí acontece no depende de la tecnología misma, sino deviene la producción social de un nuevo escenario vital, de una ecología que emana en la interacción con los medios electrónicos. Los nuevos campos de experiencia se nutren

[...] en primer lugar de la reorganización de los saberes, los flujos de información y las redes de intercambio creativo y lúdico, con las hibridaciones de la ciencia y el arte, del trabajo y el ocio; y en segundo lugar, con los nuevos modos 
de representación y acción ciudadanas, cada día más articuladores de lo local con lo mundial. (Martín-Barbero, 1999, p. 15)

En el acaecimiento de esta atmósfera sociocultural, Martín-Barbero (1999, p. 15) menciona que asistimos “a la emergencia de un ecosistema visual y sonoro, que adquiere aceleradamente tanta vigencia como el ecosistema natural", y que fundamenta tanto los procesos de socialización, representación, aprendizaje, comunicación, privacidad, creatividad e identidad de las nuevas generaciones, como el descentramiento de las instituciones y de los saberes, y sus formas tradicionales de transmisión y circulación. Por ello, entendemos que los NRT, al ser "máquinas de vincular y máquinas de crear” (Gómez, 2010, p. 50), están propiciando la producción de relaciones y obras desde el carácter lúdico de una subjetividad contemporánea emergente, que ahora es tecnomediada y que es menester rastrear.

La experiencia subjetiva, por lo tanto, está adquiriendo otro carácter dentro del entorno cibercultural (Lévy, 2007), pues allí está primando la singularidad de las interacciones de los sujetos, cada vez más fragmentados, diseminados, instantáneos y conectivos con varios lenguajes, formatos, dispositivos y redes de información, las cuales, a su vez, anidan otras formas de exclusión e inclusión social a la sociedad — del conocimiento, de la información, del consumo, de la producción capitalista.

Desde la Teoría del Actor Red (TAR), como perspectiva de análisis para modelar la acción humana y técnica (Latour, 2005), afirmamos que todos los entramados de conexiones que tienen los infantes con la digitalización cultural han de ser concebidos como juegos de relaciones que provocan momentos, acciones y efectos en sus recorridos biográficos.

A través de la TAR logramos observar que las formas de acercarnos y relacionarnos con las técnicas y los artefactos están mutando, pues la experiencia que se tiene con estos ya no se instala en la instrumentalidad para operar uno u otro mecanismo. La experiencia con estos vincula más que nunca las fibras de la sensibilidad y la corporeidad, de la movilidad del tiempo y el espacio, de la versatilidad para ser y ponerse en escena a partir de la conexión, la interactividad y la hipertextualidad, como cualidades de la atmósfera dominante (Lévy, 2007; Rueda, 2012).

En este proceso de dación de sentido de las interacciones socioculturales que se tienen con las técnicas, las máquinas y los aparatos, es donde esa plasticidad neuronal que nombra Martín-Barbero (1999) va configurando ese sensorium con el que Walter Benjamin denomina aquel entramado de nuestra percepción y nuestra sensibilidad que hace parte de la arquitectura de la experiencia subjetiva. Los marcos de referencia cultural que ya han empezado a narrar y a nombrar a ese sujeto en plural, desde la concepción, implican actos de habla que portan objetos, entidades, instituciones, actores, procesos, máquinas, mundo natural, humanos y 
un sinnúmero de elementos que conectan semióticamente una red que procura, y en la que acontece, la socialidad.

\section{¿Cómo tensionar la relación comunicación-educación desde las coordenadas narrativas y tecnicidades mediáticas?}

Teniendo presente este nuevo mapa cultural de la experiencia subjetiva, es preciso cuestionar cómo este fenómeno atraviesa la estructura de los procesos identitarios, sobre todo de las generaciones más jóvenes de la sociedad. Este interrogante sitúa otros referentes no solo para el campo comunicación-educación, en el que es necesario, desde una perspectiva reflexiva, desarrollar procesos de investigación social para comprender cómo los sujetos habitan sus contextos y cómo se forman como ciudadanos, sino también para los repertorios digitales.

Esta búsqueda refiere ir tras la huella del devenir subjetivo en la explosión tecnocultural y social de hoy, a través de las coordenadas planteadas. Pensar en cómo acontecen de forma narrativa los sujetos en la cibercultura nos muestra que la pragmática que se va cimentando a lo largo de profundas interacciones en el nuevo ecosistema comunicativo tecnomediado está conformada no solo medios masivos convencionales (radio y TV, sobre todo para nuestro caso), y medios digitales como NRT, sino también por los objetos propios de la cultura popular que se van mixturando en la confluencia tecnológica. Esta perspectiva abre nuevas rutas de sentido para comprender lo que está sucediendo dentro de la convergencia expresiva en la que hoy se mueven las generaciones, y de la que emanan ecosistemas tecnomediados en los que intervienen compleja y sistémicamente actores, roles, relatos y ambientes de creación, consumo o producción específicos.

La mixtura de estos campos de experiencia adquiere entonces modos particulares de interactividad, conectividad e hipertextualidad, que rebasan la digitalidad y dan forma a los lugares comunes que posicionan a las nuevas generaciones en diversidad de contextos en la contemporaneidad. Es por ello que es necesario dar cuenta, bajo esta perspectiva, de cómo las tecnicidades mediáticas se van llenando de una materialidad que se teje en la expresividad social de las narrativas.

Tal panorama implica grandes preguntas por su participación en los ecosistemas comunicativos, en los que se agencian diversas textualidades que ubican a los sujetos con prácticas que surgen y se producen en la cibercultura. En esta exploración no se puede desconocer que allí se están creando modelos de vida y nichos de conocimiento e intercambio basados no solo en la inteligencia colectiva y en temporalidades de interacción subjetiva conectiva, que van y se actualizan una y otra vez entre lo on y lo offline; los programas culturales mediáticos sitúan también a las nuevas generaciones como potenciales consumidores de imágenes e información, y como parte del modelo de producción capitalista que se debate 
entre las paradojas y ambigüedades del phármakon remedio y del phármakon veneno, a decir de Rueda (2012).

Phármakon remedio, en la medida que incluye a los sujetos en la llamada sociedad de la información, la globalización económica y la mundialización cultural, extendiendo las posibilidades para estar en alguna medida conectados e informados, y de experimentarse mediáticamente; phármakon veneno, por cuanto tramita el deseo una y otra vez de manera inconsciente, y crea resentimientos, angustias y precariedades al no poder obtener y usar todos los productos, objetos e informaciones que pululan de un lado para otro, lo cual genera nuevas brechas y escenarios de exclusión, y acrecienta los ya existentes (Ramírez, 2015).

Este horizonte nos reta a generar investigaciones que reconozcan los saberes, las narrativas y las actuaciones que hoy por hoy definen otras temporalidades y espacialidades de la experiencia, por lo menos en lo que respecta al relacionamiento tecnomediado. Los procesos de subjetivación están revelando cómo las tecnicidades mediáticas se van emplazando a nuevas representaciones del sujeto, donde la convergencia tecnológica funge como institucionalidad emergente y constitutiva del yo en la cibercultura, que así como robustece sus procesos de subjetivación, a la par los contamina, por los efectos del mercado y las industrias culturales.

De ahí que la mirada ha de inscribirse en el reconocimiento de esa red de significaciones culturales y de transformaciones sociales, culturales, científicas, tecnológicas y políticas que enmarcan las sociedades (Lechner, 1995), y que son evidentes en la globalización, las sociedades de mercado y el clima cultural posmoderno, que extiende sus lazos a la tecnología, los patrones de consumo, los estilos de vida y los circuitos de comunicación.

Por ello, no podemos desconocer que las formas de percepción, sensibilidad, cognición y corporeidad de las generaciones más jóvenes se instalan en esta arena propia del actual capitalismo cognitivo, como modelo económico dominante del capitalismo contemporáneo, que nos lleva a comprender que todos aquellos dispositivos de producción y regulación del capital humano (en cuanto capacidades comunicativas, cognoscitivas y afectivas) son otra forma de materialidad que se hibrida con las tecnologías de la información y la comunicación (Ramírez, 2015).

Son estas coordenadas las que han de actualizar los debates del campo comunicación-educación, dado que las tecnicidades mediáticas que los sujetos muestran al relacionarse con la digitalización de la cultura están promoviendo un contrato social y vincular que se establece en la práctica, el cual refiere, además, el plano del hacer-presente (Ricoeur, 2006, p. 1011). Lo que está sucediendo no solo con el acceso y la conectividad, sino ante todo con los patrones de consumo y producción, con el manejo del conflicto, con las redes de socialidad de las generaciones más jóvenes, con los procesos de conciencia histórica y de memoria, con la circulación, manejo, desecho y apropiación de la información, con la construcción de 
los saberes, con las brechas y los modos de inclusión o exclusión sociocultural en la bien llamada "sociedad red" (Castells, 2006) son, entre otras, situaciones objeto de estudio de la fuerza presente en el tiempo.

No obstante, el campo comunicación-educación ha de registrar que los debates en esta atmósfera dominante se inscriben dentro de las lógicas de los procesos económicos, políticos y culturales a escala mundial. Al respecto, Ramírez (2015) plantea que los procesos expresivos contemporáneos ponen en crisis la institucionalidad moderna, y recrean nuevos mecanismos de control sociotécnico y biopolítico que afectan tanto la configuración de las subjetividades individuales y colectivas, como la construcción de las representaciones hegemónicas de la realidad, que se movilizan entre los flujos de información, la novedad, la actualización constante, la velocidad y el consumo de las industrias culturales. Es el control de la vida misma y los saberes y prácticas que se producen en torno a esta los que fungen como dispositivos de biopoder, para gestionar, vigilar e inspeccionar las subjetividades. Lo que está en juego es la manufactura capitalista de la subjetividad, "donde la cultura se ha integrado a los procesos de producción y valoración económica en las sociedades contemporáneas y a su fuerza vital" (Blondieu, citado en Rueda, 2009, p. 121).

La residencia, en este contexto de control biopolítico, instala el mayor efecto del phármakon, según Rueda (2012), "como veneno, al vincularse al mercado y, al mismo tiempo, como remedio, como vía para favorecer la diseminación y democratización de saberes antes restringidos a unos pocos 'alfabetizados"' (p. 47). Asimismo, lo que se visiona en la producción social es la conformación de una economía del conocimiento que rige la arquitectura social en formas dominantes, verídicas y legítimas, tanto del conocimiento y la información, como de los contenidos de la memoria individual y social. Es la lógica del mercado la que fija aquellos saberes que se deben transmitir, preservar y mantener, como los modos de vida de las poblaciones.

En sintonía con ese discurrir, destacamos que el campo comunicación-educación ha de pensarse en relación con ciertas mutaciones determinantes en nuestra tecnicidad, enunciadas por Rueda (2012, pp. 47-49) y originarias del doble efecto phármakon:

1. Su inscripción, no en la duración, sino en las temporalidades del flujo de conciencia, encogiendo o limitando las condiciones de posibilidad de la individuación de los sujetos, pues estas se encadenan al ritmo del objeto temporal industrial constructor de la actualidad social y cultural. Este modifica y expande las maneras de percepción, atención, aprendizaje e interacción, y las inscribe a la velocidad del mercado, como uno de los motores clave del actual capitalismo. 
2. La condición fluida de la conciencia, que representa, además, los objetos e intenciones con los cuales se relaciona, y que hacen a la conciencia temporal y temporalizadora, dentro del seno social que permite el contacto entre mentes, como diría Bajtín.

3. Las disposiciones espacio-temporales del sujeto, dado que la percepción audiovisual instituye otras dimensiones, donde las funciones noéticas, psicomotoras, estéticas, se encuentran transformadas por un proceso de gramaticalización, junto con las funciones de concepción, producción y consumo.

4. La correspondencia entre el ritmo del flujo productivo, anónimo y deslocalizado del actual sistema capitalista, y la conciencia, que se caracteriza por una economía de la innovación y la rentabilidad, producente de un ciudadano que ahora es consumidor y público.

5. La trasgresión de las fronteras de lo privado y lo no privado, en cuanto a la información, al estallido de una subjetividad que exhibe su intimidad, y a las nuevas maneras de acción colectiva y política, que las sitúa en la perspectiva mercantilista y rentable del sistema.

Las mutaciones descritas expresan cómo la subjetividad no responde al individuo como tal, en calidad de totalidad, sino a la realización de una subjetividad social tensionada por un fuerte carácter maquínico y productivo que opera en el seno de las sensibilidades de la cultura, como bien lo explican Guattari y Rolnik (2006), al describir que este sentido maquínico se traduce en el artificio de "la multiplicidad de enunciamientos de subjetivación: la subjetividad está esencialmente fabricada y modelada en el registro de lo social” (p. 46). A partir de ahí ocurre la producción particular de sus modos de expresión, del deseo, de los comportamientos, de la fantasía, de la ideología, de las relaciones sociales, del cuerpo, de la memoria colectiva, de los sueños, de los modos de percibir el mundo, insertarse y laborar en él, como lo cita Ramírez (2015).

Ejemplos de este control biopolítico se pueden ver en quienes más rápido se integran a estos modos de producción: las industrias culturales de la música, los videojuegos, la moda, la publicidad, las redes sociales, la mensajería instantánea, los dispositivos digitales y todos aquellos objetos-artefactos de la cultura popular que se encargan, a gran escala, del privilegio de satisfacer y dominar, de manera irreflexiva y omnipresente, las 'necesidades' y deseos de niños, jóvenes y demás grupos poblacionales. "Se trata, pues, de un capitalismo que llega primero con las palabras, los signos, las imágenes; esto es, por máquinas de expresión que son la potencia y el poder de las sociedades de control" (Rueda, 2009, p. 121).

Con ello, el campo comunicación-educación está ante el reto de dar cuenta no solo de cómo se está modificando la forma en que los sujetos se están narrando a 
partir de la imagen, la simulación, los códigos hipertextuales y sus nuevas tecnicidades, que combinan cuerpo y máquina para ser, comunicarse, sentir y actuar, sino también de cómo estas narrativas, por un lado, potencian o languidecen sus capacidades expresivas, estéticas y culturales, y, por el otro, proyectan ideologías, prácticas, acciones, imaginarios y relaciones de poder que nos pueden permitir construir el carácter dialógico de un presente histórico común que, como dice Ricoeur (2006), hace parte de "la categoría del vivir-juntos: el mundo común de los contemporáneos" (p. 1012). Ello, en una sociedad que no escapa de los brazos del capitalismo cognitivo que hoy nos acoge, ni de la producción mercantil, heterogénea, industrializada y maquínica de la subjetividad, que "puede funcionar para lo mejor y para lo peor. Lo mejor es la creación, la invención de nuevos universos de referencia; lo peor es la mass-mediatización embrutecedora a la cual son condenados hoy en día miles de individuos" (Guattari, 2008, p. 59). Una producción mercantil que, a la vez, acrecienta las desigualdades sociales, los niveles de dominación, aislamiento cultural y pobreza de las comunidades, según las cartografías del poder.

\section{Referencias}

Arfuch, L. (2002). El espacio biográfico. Dilemas de la subjetividad contemporánea. Buenos Aires: Fondo de Cultura Económica.

Benveniste, E. (1978). El aparato formal de la enunciación. En Problemas de lingüística general (t. 1). México, D. F.: Siglo Veintiuno.

Buckingham, D. (2002). Crecer en la era de los medios electrónicos. Madrid: Morata.

Buckingham, D. (2008). Más allá de la tecnología. Aprendizaje infantil en la era de la cultura digital. Buenos Aires: Manantial.

Castells, M. (2006). La sociedad red: una visión global. Madrid: Alianza.

Guattari, F. (2008). La ciudad subjetiva y post-mediática. La polis reinventada. Cali: Fundación Comunidad. [Selección y traducción de textos: Ernesto Hernández B. y Carlos Enrique Restrepo].

Guattari, F. y Rolnik, S. (2006). Micropolítica. Cartografías del deseo. Madrid: Traficantes de Sueños.

Gómez, R. (2010). Procurarse sentido en la ciudad contemporánea: jóvenes y nuevos repertorios tecnológicos (tesis inédita de doctorado). Universidad Pedagógica Nacional, Bogotá, Colombia.

Igarza, R. (2008). Nuevos medios. Estrategias de convergencia. Buenos Aires: La Crujía. 
Latour, B. (2005). Reensamblar lo social. Una introducción a la teoría del actor-red. Buenos Aires: Manantial.

Lechner, N. (1995). Cultura política y gobernabilidad democrática. México, D. F.: Fondo de Cultura Económica.

Lévy, P. (2007). Cibercultura. La cultura de la sociedad digital. Barcelona: Anthropos.

Martín-Barbero, J. (1999). La educación en el ecosistema comunicativo. Comunicar, (13), 13-21.

Martín-Barbero, J. (2002). La globalización en clave cultural. Ponencia presentada en el Coloquio Internacional Efectos Globalismo y Pluralismo. Montreal, Canadá. Guadalajara: ITESO Universidad Jesuita de Guadalajara.

Martín-Barbero, J. (2003). La educación desde la comunicación. Bogotá: Norma.

Muñoz, G. (enero-junio de 2010). ¿De los “nuevos medios” a las "hipermediaciones"? Revista Latinoamericana de Ciencias Sociales Niñez y Juventud, 8(1), 9-16. Recuperado de dialnet.unirioja.es/descarga/articulo/3254267.pdf

Ramírez, A. (2015). Capitalismo cognitivo y producción de subjetividades infantiles y juveniles. En R. Rueda, A. Ramírez y G. Bula (eds.), Cibercultura, capitalismo cognitivo y educación. Conversaciones y re(di)sonancias. Bogotá: Universidad Pedagógica Nacional.

Ricoeur P. (1995). Tiempo y narración I. Configuración del tiempo en el relato histórico. México, D. F.: Siglo Veintiuno.

Ricoeur P. (1995a). Tiempo y narración II. Configuración del tiempo en el relato de ficción. México, D. F.: Siglo Veintiuno.

Ricoeur P. (1999). Identidad narrativa. En: Historia y narratividad. Barcelona: Paidós.

Ricoeur P. (2004). Volverse capaz, ser reconocido. Discurso de recepción del premio Kluge. Biblioteca del Congreso de los Estados Unidos, Washington, Estados Unidos.

Ricoeur P. (2006). Tiempo y narración III. El tiempo narrado. México, D. F.: Siglo Veintiuno.

Rueda, R. (21 de octubre de 2004). Tecnocultura y sujeto cyborg: esbozos de una tecnopolítica educativa. Nómadas, (21), 70-81. 
Rueda, R. (2008). Para una pedagogía del hipertexto: una teoría de la deconstrucción y la complejidad. Barcelona: Anthropos.

Rueda, R. (Enero-junio de 2009). Convergencia tecnológica: síntesis o multiplicidad política y cultural. Signo y pensamiento, 28(54) 114-130.

Rueda, R. (2011). Capitalismo cognitivo y transformaciones tecno-cognitivas. Inédito. Curso Cibercultura, Subjetividades y Educación, Universidad Pedagógica Nacional, Bogotá.

Rueda, R. (Abril de 2012). La sociedad de la información y el conocimiento: tecnicidad, phármakon e invención social. Nómadas, (36), 43-55.

White, H. (1992). El contenido de la forma. Barcelona: Paidós. 
